\title{
3
}

\section{MODELO PROPOSTO: \\ O SISTEMA HÍBRIDO DE TOC APLICADO AO SCM APOIADO PELO VMI-B2B}

A conjuntura conceitual até aqui pesquisada, desenvolvida e discutida, teve como objetivo central propiciar o entendimento e a compreensão para se viabilizar o SCM baseado nos preceitos da TOC.

É sensato também destacar que a pesquisa foi direcionada (espera-se que com a devida prudência) em se evidenciar não somente os prováveis benefícios, mas também as possíveis dificuldades, principalmente culturais e comportamentais, inerentes a todos os processos de transformação empresariais.

Contudo, para se atender a outro propósito desta pesquisa, mais precisamente em tornar exeqüível a aplicação prática da TOC no SCM em um processo de suprimentos, é necessário salientar que é recomendável agregar outras soluções e ferramentas auxiliares, a fim de suportar a transposição de toda a arquitetura teórica para a realidade corporativa.

Neste aspecto, a implementação real em uma empresa (a ser abordado no capítulo 4) contou com a adoção do vendor-managed inventory (VMI) e do business-to-business (B2B), como suplementos para a complementação da TOC na sustentação de uma solução robusta ao SCM, com resultados concretos, face às dificuldades envolvendo os conceitos teóricos desta metodologia versus a implantação real.

As Figuras 28 e 29 exibem uma proposta para este novo relacionamento entre fornecedores, fabricantes, distribuidores e varejistas, direcionando onde utilizar o gerenciamento dos pulmões para os estoques de produtos acabados, a fim de controlar o fluxo do SCM, no qual o VMI-B2B se integram como principal recurso de suporte para:

- A troca dinâmica de informações nos pontos de convergência, entre todos os envolvidos da SC, desde os varejistas e lojistas até os fornecedores;

- O compartilhamento dos planos de vendas e de produção;

- Os dados sobre a situação, em tempo real, dos estoques entre todos os parceiros. 


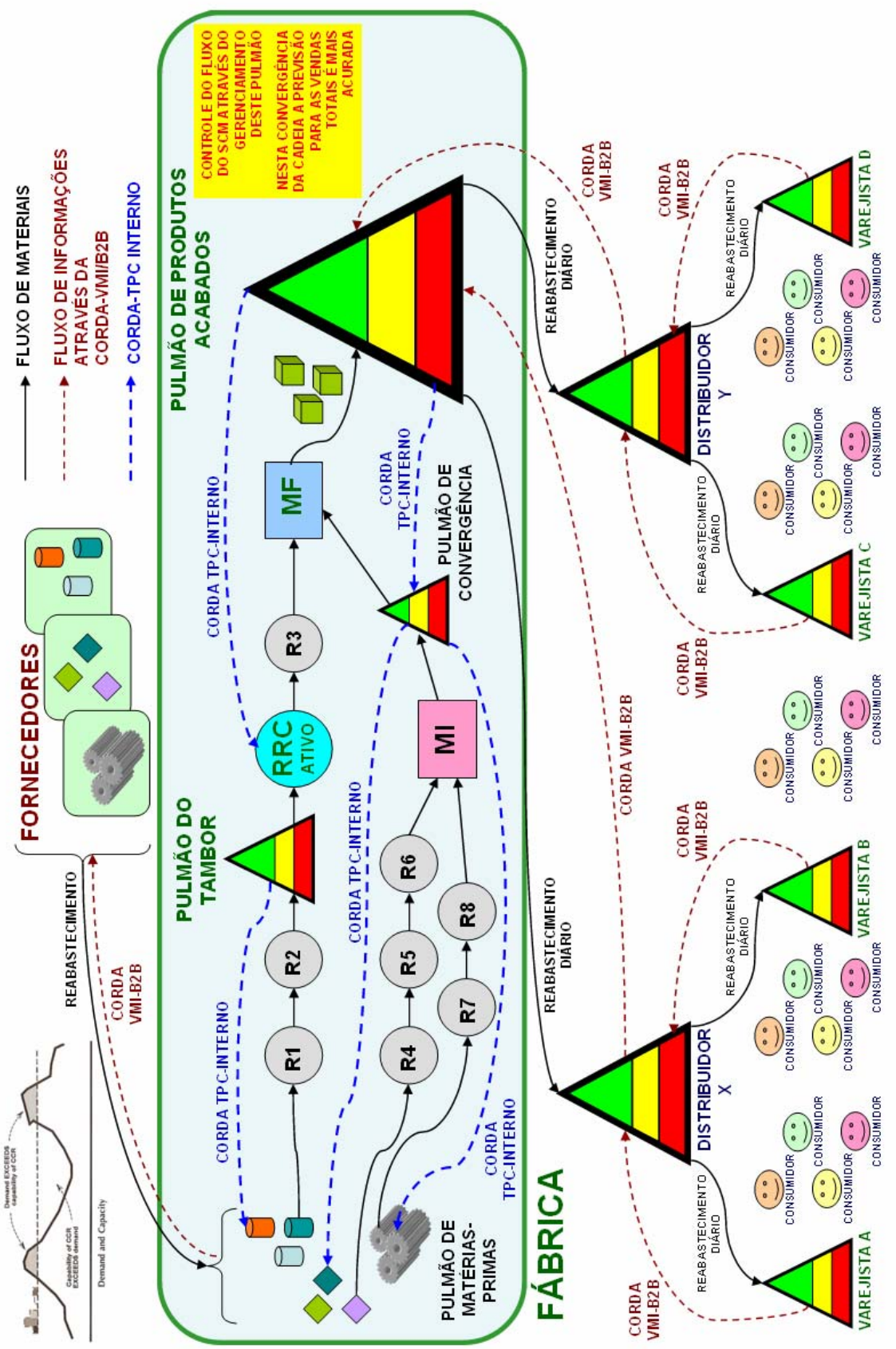

Figura 28 - Proposta TOC-VMI-B2B para o SCM com RRC ativo (demanda maior do que a capacidade do recurso mais limitado da cadeia). 
A Figura 28 representa o processo proposto para uma cadeia de suprimentos com um RRC ativo (explanado nas seções 2.3.3, 2.3.5 e 2.3.6.4), sendo descrita segundo a ordem lógica do sistema "puxado" (exposto nas seções 2.3.2, 2.3.3, 2.3.4 e 2.3.6.3):

- $1^{\circ}$. - Os pulmões dos varejistas A, B, C, e D diminuem conforme os consumidores compram os produtos ao longo de um dia;

- $2^{\circ}$. - As cordas "VMI-B2B" informam em tempo real aos distribuidores $\mathrm{X}$ e $\mathrm{Y}$ sobre a necessidade de reposição das mercadorias consumidas nos varejistas;

- $\quad 3^{\circ}$. - Os distribuidores reabastecem os pulmões dos varejistas A, B, $\mathrm{C}$ e D imediatamente no dia seguinte;

- $4^{\circ}$. - O processo se propaga, comportando-se como uma reação em cadeia, onde outras cordas "VMI-B2B" informam instantaneamente a fábrica acerca de todas as mercadorias debitadas dos pulmões dos distribuidores $\mathrm{X}$ e Y durante o dia;

- $\quad 5^{\circ}$. - Do mesmo modo, o pulmão de produtos acabados da fábrica reabastece os pulmões dos distribuidores $\mathrm{X}$ e $\mathrm{Y}$ imediatamente no dia seguinte;

- $6^{\circ}$. - O consumo do pulmão de produtos acabados da fábrica movimenta toda a necessidade do fluxo interno de manufatura de acordo com a programação TPC;

- $\quad 7^{\circ}$. - As cordas "TPC-interno" garantem o fluxo contínuo, em que o consumo dos pulmões do tambor e de convergência disparam as necessidades para entrada de matérias-primas no sistema, bem como a demanda para montagens intermediárias, garantindo que todo o processo de manufatura esteja subordinado ao RRC (abordado na seção 2.2.1.3);

- $8^{\circ}$. - Novamente uma corda "VMI-B2B" informa instantaneamente aos fornecedores sobre todos os itens subtraídos do pulmão de matérias-primas durante o dia;

- $9^{\circ}$. - Seguindo o mesmo procedimento da fábrica e dos distribuidores, os fornecedores reabastecem o pulmão de matériasprimas da fábrica imediatamente no dia seguinte.

Resumindo, todo o processo descrito subordina a cadeia de suprimentos ao seu principal objetivo: atender a todas as oportunidades de vendas, não 
desperdiçando os clientes que vêm até você (KENDALL, 2007), garantindo mercadorias prontamente disponíveis nos varejistas e lojistas, a fim de atender todos consumidores finais (discorrido na seção 2.3.6.3, "O segundo passo do processo de melhoria contínua: explorar a restrição no SCM").

É particularmente importante destacar que toda a rede de comunicação, interconectando todos os pulmões através das cordas "VMI-B2B" e cordas "TPCinterno", comporta-se como o elemento fundamental do mecanismo responsável por subordinar toda a cadeia ao RRC ativo: a informação precisa, e em tempo real.

E a política de re-suprimento diária é essencial para complementar o desempenho da informação. Aqui vale ressaltar que a periodicidade de reabastecimento pode ser ajustada, dependendo das características peculiares que porventura um SCM necessitará demandar.

Todavia, é racional pressupor que longos períodos com o RRC ativo denotam a perpetuidade de uma demanda maior do que a capacidade da fábrica em atendê-la.

Isto posto, é necessário que os dirigentes de todas as empresas envolvidas no processo tomem decisões de abrangência estratégica e global. E segundo todo o processo de raciocínio lógico desenvolvido na seção 2.3.3 (o método TPCsimplificado), terminará impreterivelmente em três escolhas possíveis:

a. Sustentar o fluxo da cadeia subordinada ao RRC ativo, até a depreciação completa do pulmão de produtos acabados na fábrica, e subsequentemente de todos os outros pulmões reduzidos nos distribuidores e varejistas;

b. Aumentar a capacidade do RRC ativo (quarto passo do processo de melhoria contínua: elevar a restrição);

c. Declinar em atender aos pedidos dos clientes menos rentáveis, e gerenciar a cadeia de suprimentos segundo o método TPC-simplificado, em que a cadeia de suprimentos opera em regime com capacidade superior à demanda.

Se a alternativa "c" for a decisão mais adequada para os interesses do negócio, a Figura 29 representa então o processo proposto, porém adaptado para uma cadeia de suprimentos sem um RRC ativo, regido pelo método TPCsimplificado. 


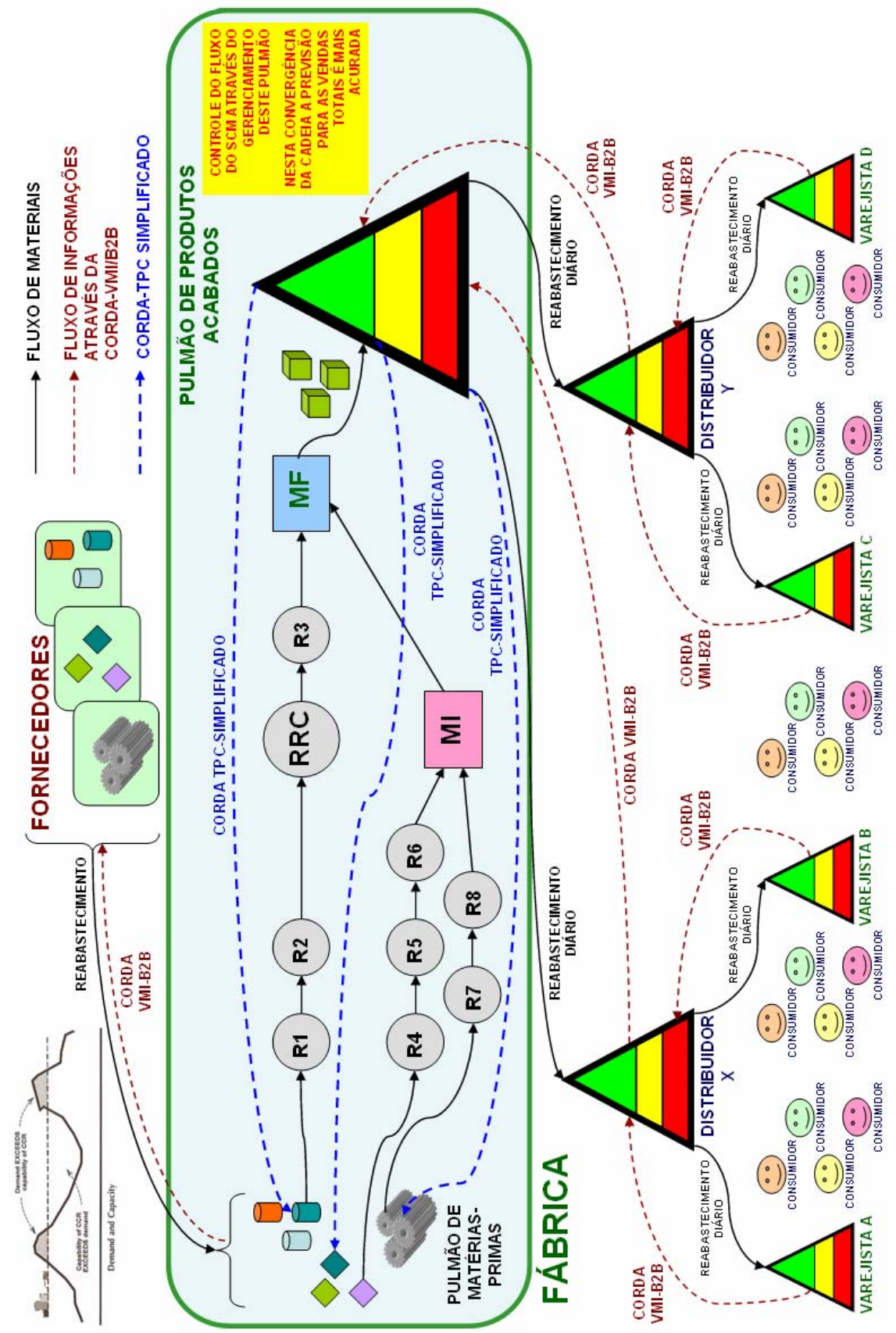

Figura 29 - Proposta TOC-VMI-B2B para o SCM sem RRC ativo (TPCSimplificado) (demanda menor do que a capacidade do recurso mais limitado da cadeia). 
A descrição do processo da Figura 29, também convencionado ao sistema "puxado", é congruente com o processo anteriormente descrito para a Figura 28, diferenciando-se apenas pelo emprego da corda "TPC-simplificado" dentro da fábrica, responsável por cadenciar o fluxo de entrada de materiais e fabricação de acordo com o consumo do pulmão de produtos acabados da fábrica.

Contudo, é particularmente relevante apresentar um último cenário, posto que este reflete exatamente a aplicação prática apresentada para evidenciar a viabilidade e os benefícios da proposta (a ser abordada no capítulo 4).

Se porventura a cadeia de suprimentos opera em regime com capacidade superior à demanda, pode também ser atraente para o negócio empregar o modelo descrito pela Figura 28. A diferença é que, apesar de não haver um RRC ativo, um recurso pode vir a ser eleito para exercer esta função, para o fim específico de gerenciar a cadeia de suprimentos parametrizada segundo o TPC tradicional. Porém, é prudente relembrar que esta escolha é contrária às recomendações de Schragenheim e Dettmer (2000b), conforme discutido na seção 2.3.3.

\subsection{CONCLUSÕES SOBRE O MODELO PROPOSTO}

Na fábrica, a previsão da demanda é mais precisa, pois as estimativas são baseadas para toda a carteira de clientes. Neste ponto da cadeia de suprimentos, todas as flutuações de mercado estão diluídas pois, na média geral, é altamente provável que os produtos não vendidos em alguns pontos de consumo, venham a ser vendidos em outras lojas no mesmo período (quanto maior a amostra da população, menor o desvio padrão).

O ciclo de abastecimento deve obedecer uma periodicidade que seja suficiente para repor todos os pulmões reduzidos nos distribuidores e varejistas, assim que os mesmos são consumidos (se possível diariamente, dependendo do tipo de produto).

Para atender prontamente estas necessidades de reposição, é necessário que haja uma quantidade de produtos acabados em estoque para atender esta demanda global da cadeia. Porém, apesar das elevadas quantidades de produtos acabados nas fábricas, o giro de estoque neste ponto da cadeia é rápido, justamente por se atender a demanda total de todos os clientes da cadeia.

A periodicidade ajustada de reabastecimento (ciclo diário) é essencial para evitar o efeito chicote. 
Com isto, conforme mencionado por Umble e Umble (2002), é evidente a similaridade da forma de aplicação e dos potenciais benefícios propostos tanto pela TOC como pelo VMI, denotando que estes métodos podem, de forma complementar, serem empregados de maneira a alavancarem mutuamente as suas potencialidades, através da integração de todos os parceiros na cadeia de suprimentos, desde os fornecedores de insumos primários até os clientes finais.

No capítulo 4, uma aplicação real é apresentada, na qual a TOC, o VMI e o B2B foram aplicados conjuntamente em associação ao SCM da Siber do Brasil S.A., uma empresa multinacional de médio porte, localizada no Brasil.

A solução implantada utiliza um sistema de ERP chamado Customer Integrated System (CIS). O módulo logístico do CIS administra uma ferramenta VMI, a qual trabalha na redução do efeito chicote, com consequente minimização do inventário geral.

O TPC da TOC é adotado internamente em substituição ao MRPII, para administração da logística e estoques internos, através de um planejamento produtivo com foco no cliente e na gestão dos recursos restritivos de capacidade.

A interface entre a empresa e seus fornecedores é efetuada de forma eletrônica, através de um portal B2B na internet, garantindo agilidade e eficiência na distribuição das informações.

Serão apresentados os resultados obtidos no SCM após a solução TOC-VMIB2B ter sido implementada, permitindo ao sistema operar como um APS através da internet. 
